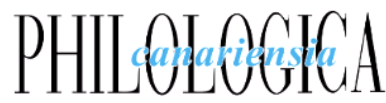

Philologica Canariensia 22 (2016), 7-24 eISSN: 2386-8635

Recibido: 14 de abril de 2016; aceptado: 6 de junio de 2016

Publicado: 25 de octubre de 2016

DOI: 10.20420/PhilCan.2016.100

\section{PROHIBIDO HABLAR CASTELLANO EN EL RECREO O LOS MÉTODOS PARA ENSEÑAR FRANCÉS EN ESPAÑA A COMIENZOS DEL SIGLO XX*}

\author{
M. a ÁNGELES GARCÍA ARANDA \\ Universidad Complutense de Madrid
}

RESUMEN: Este artículo presenta el análisis del contenido, la estructura, las fuentes y el contexto de la Colección de voces, frases y locuciones castellanas con su traducción al francés (1904), texto que hasta la fecha ha pasado desapercibido para los investigadores y que constituye un buen ejemplo de los materiales utilizados para la enseñanza de francés como segunda lengua.

PALABRAS CLAVE: lexicografía, siglo XX, francés como lengua extranjera

It is forbidden to speak Spanish on the playground, or the methods of teaching French in early twentieth-century Spain

ABSTRACT: This article presents an analysis of the content, structure, sources and context of the Colección de voces, frases y locuciones castellanas con su traducción al francés (1904), a text that remains largely unexplored and which provides a good example of the materials used to teach French as a second language.

KEYWORDS: lexicography, twentieth century, French as a second language

\section{INTRODUCCIÓN}

A comienzos del pasado siglo, la imprenta de Pío de Azagra saca a la luz una Colección de voces, frases y locuciones castellanas con su traducción al francés compuesta por un padre del Colegio de los Sagrados Corazones de Miranda de Ebro (1904), un repertorio que compila, a partir de diferentes ámbitos designativos, el vocabulario básico de nuestra lengua y su traducción al francés, esto es, uno de los muchos materiales que se han utilizado para aprender la lengua del país vecino en España.

Desde que Gonzalo Suárez Gómez defendió su tesis doctoral sobre La enseñanza del francés en España (Comentario a una bibliografía establecida hasta 1850), ${ }^{1}$ varios son los catálogos, repertorios e investigaciones (muy bien elaborados todos ellos) que han recopilado los manuales de enseñanza de francés en nuestro país a lo largo de la historia, pero ninguno da cuenta de esta Colección: ni en La enseñanza del francés en

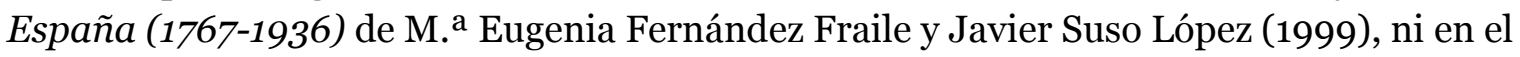


Repertorio de gramáticas y manuales para la enseñanza del francés en España (1565-1940) de Denise Fischer, Juan F. García Bascuñana y María Trinidad Gómez (2004), ni en los "Materiales para la enseñanza del francés en España: aproximación a los manuales publicados entre los Siglos XVI y XX” de Juan F. García Bascuñana (2005), ni en el Repertorio de manuales para la enseñanza del francés en España (siglo XX): con qué libros los españoles hemos aprendido francés en el siglo XX de Javier Suso López y M. ${ }^{a}$ Eugenia Fernández Fraile (2008), ni en "La Lexicographie française-espagnol: tradition et modernité" de Ascensión Sierra Soriano (2010) consta alusión alguna al texto del Colegio de Miranda de Ebro.

Este artículo presenta el análisis del contenido y la estructura de la obra, su explotación didáctica, sus fuentes y el contexto en que fue compuesta, con el objetivo de contribuir a la historia de la Lexicografía escolar del español, campo de investigación que cuenta todavía con una trayectoria muy breve.

\section{CONTEXTO: LA ENSEÑANZA DEL FRANCÉS EN ESPAÑA A COMIENZOS DEL SIGLO XX}

Como se ha puesto de manifiesto en numerosas ocasiones (cfr., por ejemplo, Cazorla Vivas, 2002; Domínguez Ortiz, 1989; Fernández Fraile, 1995; Fernández Fraile y Suso López, 1999; García Bascuñana, 1996; García Bascuñana, Lépinette y Roig, 1996; Gemmingen y Höfler, 1988; Lázaro Carreter, 1949; Simon Palmer, 1972), circunstancias políticas y culturales como la llegada de los Borbones al trono español o la Ilustración motivaron que, especialmente desde el siglo XVIII, la influencia del francés se hiciera cada vez más patente en todos los ámbitos de la vida cotidiana española (lengua, costumbres, moda, corte, artes, conocimientos científicos...), tanto que el francés llegó, ya en el siglo XIX, a entrar en los planes de estudio como lengua obligatoria en la enseñanza secundaria.

Este contexto de relaciones políticas, sociales, económicas y culturales entre Francia y España tuvo importantes consecuencias sobre la enseñanza de lenguas, pues en ambos países despertó el deseo por aprender la lengua del pueblo vecino, lo que supuso la publicación, fundamentalmente en los siglos XVIII y XIX, de numerosas gramáticas, diccionarios y ortografías tanto bilingües como monolingües, en Francia sobre el español y en España sobre el francés (vid. Cazorla Vivas, 2002 y 2014).

\subsection{El Colegio de los Sagrados Corazones de Miranda de Ebro}

El Colegio de los Sagrados Corazones de Miranda de Ebro, ${ }^{2}$ primera casa española de esta Congregación, fue fundado a finales del siglo XIX (1880) por el Padre Román Desmarais, quien hubo de buscar acomodo en España para sus seminaristas y hermanos cuando fue expulsado de su Casa parisina. Tras recorrer La Rioja, Navarra y Burgos, elige Miranda de Ebro por los terrenos para la ubicación del colegio que ofrecía el antiguo convento de San Francisco y por las ventajas que suponía la situación geográfica de Miranda (cuatro líneas de ferrocarril, cercanía a Francia, excelentes comunicaciones). En los años siguientes se autoriza la instalación de la comunidad religiosa (1880), comienzan la formación del Noviciado, llegan los primeros religiosos (1883, la mayoría procedentes de Francia) y, tras la incorporación del colegio a la Universidad de Valladolid, comenzó el primer curso de externos (1888).

La presencia del francés en el Colegio estaba justificada. De hecho, en el texto sobre "Los primeros pasos del Colegio",3 en el que se recoge el reglamento de 1897 por el que se 
regía el Colegio (muy parecido al de otros colegios religiosos, cuyo objetivo era una educación religiosa basada en una férrea disciplina), además de explicar las obligaciones de los alumnos concernientes a su vida diaria (prohibido tener reloj, dinero, cajas cerradas con llave o libros o escritos no autorizados, compartir los regalos de comer o beber, imposibilidad de abandonar la estancia en que estaban sin permiso del religioso que estaba al cargo, la obligación de escribir a las familias al menos una vez al mes), se explicita que en el recreo "era obligatorio hablar en francés la mayor parte del año".

El francés fue, pues, una lengua importante en la historia de este Colegio, lo que se vio reforzado por la legislación vigente, pues, desde la Ley Moyano, las lenguas vivas entraron como materias obligatorias en los planes de estudio. Esta nueva situación propició

la aparición de un nuevo tipo de usuario: los escolares, y esta importante novedad, junto con el progresivo aumento de los viajes y de los intercambios comerciales, que permite que los viajeros y comerciantes se sigan contando entre los destinatarios de obras, serán los causantes de que en el siglo XIX abunden gramáticas que enseñan el uso correcto del idioma; y al mismo tiempo manuales que contienen frases usadas habitualmente en la conversación y diálogos empleados para enseñar a la gente los rudimentos de la comunicación, cartas comerciales o privadas, que pueden ser útiles tanto para las relaciones laborales como personales y, cómo no, diccionarios, para ayudar en las traducciones y aprender vocabulario y otras informaciones contenidas en ellos. (Cazorla Vivas, 2002, 18)

\subsection{Legislación y Planes de estudio}

En 1904, año en que aparece la Colección, estaba vigente el Plan de estudios de 1900 (año en que se creó el Ministerio de Instrucción Pública), plan fruto de los vaivenes políticos que vive España en estos años y en el que perdura la Ley general de Instrucción pública de 1857 firmada por Claudio Moyano, en donde el francés había entrado a formar parte de la enseñanza secundaria como materia obligatoria (cfr. Fernández Fraile y Suso López, 1999).

Según describe M. ${ }^{a}$ Eugenia Fernández Fraile en el capítulo sobre "La enseñanza/ aprendizaje del francés entre 1857 y 1936" (1995, 195-361), el Plan de estudios de 1900 establecía como obligatorias para los alumnos dos lenguas vivas en el Bachillerato (que constaba de 6 cursos), en la sección de Estudios Generales, es decir, para todos los alumnos. Las lenguas vivas serán impartidas de modo sucesivo: primero, el Francés, durante dos años $\left(3^{\circ}\right.$ y $4^{\circ}$ cursos, a razón de "clase alterna de una hora y media por semana", es decir cuatro horas y medias); posteriormente, una segunda lengua viva es ofrecida de modo obligatorio a la elección de los alumnos (inglés o alemán), durante otros dos años $\left(5^{\circ}\right.$ y $6^{\circ}$ curso), a razón de una "clase alterna de una hora", o sea tres por semana. Una modificación de 1903 (Real Decreto de 6-IX-1903) elimina la segunda lengua viva.

Los programas oficiales de estos Planes de estudio señalan que los objetivos de la enseñanza de las lenguas vivas deben incluir también la lengua hablada, si bien "hay que tener presente que sigue sin concretarse una concepción de la lengua como hecho eminentemente oral: la práctica oral de la lengua es vista como un elemento añadido, deseable; el objeto principal del trabajo debe consistir en la lectura, la traducción y la redacción" (Fernández Fraile, 1995, 250). Ello tendrá importantes consecuencias en las metodologías de aprendizaje de lenguas pues se impondrá, primero en Francia y después en Europa, el método directo, la supremacía de la lengua oral, lo que 
chocaba de frente, sin posibilidad aparente de compromiso, con el método entonces imperante: este respondía a una concepción de la lengua que primaba por un lado un objetivo formativo y cultural, y por otro concretaba los objetivos prácticos en un manejo escrito de la lengua (traducción, redacción), basado en el conocimiento gramatical, e ignorante de la lengua hablada (solamente la lectura). (Fernández Fraile, 1995, 251)

En España, no obstante, en estos primeros años del siglo XX, "no hemos encontrado manuales que puedan definirse como propios del método directo" (Fernández Fraile y Suso López, 1999, 274).

\subsection{Materiales utilizados en la enseñanza de francés}

Si en España no había penetrado aún el método directo, ¿qué materiales se utilizaron en la enseñanza de francés en España en estas fechas? Según el repertorio de Denise Fischer, Juan F. García Bascuñana y María Trinidad Gómez (2004) y el catálogo que recogen Javier Suso López y M. ${ }^{\text {a }}$ Eugenia Fernández Fraile (2008), los españoles aprendían francés a comienzos del siglo XX con las adaptaciones del método Ahn que hicieron Eugenio de Ochoa, Átalo Castañs y Henry Mac-Veigh, con la Gramática razonada histórico crítica de la lengua francesa (1889), con el Método razonado teórico-práctico para la enseñanza del francés (1891), con los Temas de traducción (1889) y con la Crestomatía francesa de Fernando Araujo Gómez (1890), con el Ollendorf reformado. Gramática francesa y método para aprenderla de Eduardo Benot (1858), con el Novísimo Chantreau o Gramática francesa de Bergnes de las Casas (1845), con el método de Maximilian Berlitz, con la Langue française y el Compendio de gramática francesa de Antonio Boyer (1903), con los Elementos de gramática francesa en sus relaciones con la de la lengua castellana: método teórico-práctico de Cayetano Castellón y Pinto (1892), con la Gramática francesa de José María Castilla (1898), con los Elementos de gramática francesa (1891) de Lucio Elices Serrano, con la Gramática francesa de Joaquín García Bravo (1902), con los manuales del método ideado por Emilio Otto y Gustavo Kordgien, con la Grammaire théorique et pratique pour apprendre la langue française de Antonio Gaspar del Campo (1886), con la Fonotecnia francesa y con El francés castizo del siglo XX al alcance de todas las inteligencias por Carlos Lacôme Gendry Arquiaga (1899 y 1904, respectivamente), con el Curso de francés y con la Práctica francesa de Mario Méndez Bejarano (1890 y 1894, respectivamente), con la Nueva gramática francesa y trozos de traducción militares de Juan Ostenero y Velasco (1881), con el método Robertson, con las Lecciones de lengua francesa de Carlos Soler y Arqués (1884), y con el Método Ugarte para aprender a traducir, hablar y escribir con soltura en lengua francesa de Eduardo Ugarte y Albizu (1900).

La mayoría de estos textos, pese a la renovación metodológica que pregonan, no son sino representantes de las tendencias innovadores que se desarrollaron en Europa en la centuria anterior: el método tradicional o gramática-traducción, el método natural o conversacional, los libros de diálogos y conversación y la traducción interlineal, esto es, gramática tradicional (con definiciones y tipologías de las partes de la oración, reglas sintácticas y algunos capítulos sobre pronunciación), ejercicios prácticos, diálogos, refranes y textos literarios, nada que no hubiera aparecido con anterioridad en los manuales de 
enseñanza de segundas lenguas (Colombo Timelli, 1992 y 1998; Sánchez Pérez, 1992 y 1997).

En cuanto al léxico, en las últimas décadas del siglo XIX y primeras del XX continuaron publicándose los diccionarios decimonónicos de Vicente Salvá (con numerosos añadidos), Melchor Manuel Núñez de Taboada, Domingo Gian Trapani, Domingo Gildo, Felipe Picatoste, Nemesio Fernández Cuesta y Picatoste, Francisco Corona Bustamante, Marie Jean Blanc Saint-Hilaire, Pedro Martínez López y F. Muriel, Antonio Bergnes de las Casas, L. Tolhausen, G. Aquenza y A. Galbán, esto es, conviven diccionarios generales con amplias nomenclaturas y artículos lexicográficos muy detallados - como los de Pedro Martínez López y F. Muriel, Domingo Gildo o Núñez de Taboada, que inspiró otros repertorios posteriores- con diccionarios portátiles o de bolsillo que reúnen voces comunes y sencillas -como los de Saint-Hilaire, L. Tolhausen o G. Aquenza- con diccionarios enciclopédicos deudores de los grandes diccionarios monolingües franceses -como los de Salvá, Fernández Cuesta o Picatoste- y con repertorios temáticos o por ámbitos designativos 4 (Alvar Ezquerra, 2013; Bruña Cuevas, 2004; Cazorla Vivas, 2002 y 2014; García Bascuñana, 1996; Quemada, 1968; Verdonk, 1991).

Junto a estos repertorios, y tal y como muestra la Colección de voces, frases y locuciones castellanas con su traducción al francés, se compusieron otros repertorios breves, con sencillos artículos lexicográficos, sin demasiadas pretensiones y que debieron resultar también muy útiles para la enseñanza del francés a escolares.

\section{LA COLECCIÓN DE VOCES, FRASES Y LOCUCIONES CASTELLANAS CON SU TRADUCCIÓN AL FRANCÉS}

\subsection{Contenido y estructura}

La Colección de voces, frases y locuciones castellanas con su traducción al francés ${ }^{5}$ es un manualito de apenas sesenta páginas, sin introducción ni prólogo ni preliminares, que recoge, en diferentes ámbitos designativos, el léxico relacionado con la vida escolar que se desarrollaba dentro del Colegio de los Sagrados Corazones, a saber:

1. Fórmulas de cortesía para saludar, preguntar, responder, pedir permisos, etc.

\begin{tabular}{|l|l|}
\hline Buenos días tenga V., Padre & Bonjour, mon Père \\
\hline Felices los tenga V., amigo & Bonjour, mon ami \\
\hline $\begin{array}{l}\text { Le doy a V. los buenos días, -las buenas } \\
\text { tardes, -las buenas noches }\end{array}$ & $\begin{array}{l}\text { Je vous souhaite le bonjour, -le bonsoir, -une } \\
\text { bonne nuit }\end{array}$ \\
\hline ¿Qué tal está V.? & $\begin{array}{l}\text { Comment allez-vous? } \\
\text { (fam.) Comment ça va-t-il? }\end{array}$ \\
\hline Estoy bien, -estoy bueno, gracias a Dios & $\begin{array}{l}\text { Je vais bien, -je me porte bien, grâce à Dieu } \\
\text { (Dieu merci) }\end{array}$ \\
\hline Estoy muy bien & Je me porte à merveille \\
\hline Me alegro & Je m'en réjouis (j'en suis bien aise) \\
\hline
\end{tabular}


2. Estudios y clases.

\begin{tabular}{|l|l|}
\hline Hay que estudiar, -escribir & Il faut étudier, -écrire \\
\hline Es preciso atender, -aplicarse & Il faut écouter, -s'appliquer \\
\hline $\begin{array}{l}\text { Es muy aplicado, -estudioso, -está } \\
\text { muy atento }\end{array}$ & Il est très appliqué, -studieux, -attentif \\
\hline Es muy trabajador & $\begin{array}{l}\text { C'est un trabailleur, -(fam.) un piocheur, } \\
\text { un bûcheur }\end{array}$ \\
\hline Es muy listo, -despejado & Il est très intelligent, -dégourdi \\
\hline Lo entiende todo & Il comprend tout \\
\hline Es muy perezoso, -holgazán & Il est très paresseux, -fainéant \\
\hline Es muy corto de alcances & Il est très borne \\
\hline No se mata & $\begin{array}{l}\text { Il ne se tue pas, -(fam.) Il ne se foule pas } \\
\text { la rate }\end{array}$ \\
\hline (fam.) No inventó la pólvora & (fam.) Il n'a pas inventé la poudre \\
\hline (fam.) Es un flojo rematado & (fam.) C'est un paresseux fieffé \\
\hline (fam.) Está V. siempre papando moscas & $\begin{array}{l}\text { (fam.) Vous êtes toujours à Bayer } \\
\text { aux corneilles }\end{array}$ \\
\hline (fam.) iPor qué no atiende V. en clase? & $\begin{array}{l}\text { Pourquoi n'êtes-vous pas attentif en clase } \\
\text { (ne faites pus attention...)? }\end{array}$ \\
\hline
\end{tabular}

3. Del recreo, en donde aparecen frases como ¿qué lengua se habla en este recreo?, hay que hablar francés, está prohibido hablar en castellano, haga V. pasar la bola a los que hablen castellano, si habla $V$. castellano, le van a castigar, copiará V. el verbo..., estudiará $V$. estos renglones, no hay que salir del patio sin pedir permiso, sin avisar, me ha pegado un puntapié, un puñetazo, un palo, me han estirado de las orejas, me han arañado, me han tirado una piedra, ¿cuánto falta para acabarse el recreo?, dentro de unos minutos van a tocar el primer tañido, ya se puede hablar castellano, iqué pronto pasó el recreo!

4. El capítulo más extenso (ocupa diez páginas frente a las dos o tres que se emplean para el resto de secciones) y cuidado de todos es el dedicado a los juegos; en él se revisa el vocabulario utilizado, así como las reglas o las frases y canciones usadas, del juego de pelota, del frontón, del cazador, de los pozos (hoyos), del pelotón, del marro, del gavilán, de las bolitas, del tío Gazapejos (del père Jacob, en francés), de la bandera, del carabá, del croquet, del ajedrez, del trompo, de la cometa, del columpio, de la honda, de los zancos, del aro, de la lotería, del dominó, de la rana, de las bolas, de los bolos, del boliche, del hinque, del rompecabezas, del correcalle, del cero, de la primera palmada, de las tres en raya, "a la una la mula" o de la gallina ciega.

5. Del paseo, que describe perfectamente la salida de los escolares al campo (salirse de las filas, ir a la sombra, tener sed, rozar el zapato, matar una rana, una lagartija o una salamandra, coger un grillo, un saltamontes o un bicho).

6. El cuerpo y sus miembros es un apartado muy breve que detalla el léxico del cuerpo humano y las acciones relacionadas con él. 


\begin{tabular}{|l|l|}
\hline $\begin{array}{l}\text { La cabeza, -el cerebro, -el cráneo, } \\
\text {-los cabellos }\end{array}$ & La tête, -le cerveau, -le crâne, -les cheveux \\
\hline $\begin{array}{l}\text { La frente, -el ojo, -los ojos, -las cejas, } \\
\text {-las pestañas, -el párpado }\end{array}$ & $\begin{array}{l}\text { Le front, l'oeil, -les yeux, -los sourcils, -les } \\
\text { cils, -la paupière }\end{array}$ \\
\hline Un diente, -una muela & Une dent, -une molaire \\
\hline Limpiarse los dientes & Se laver les dents \\
\hline Enjuagarse la boca & Se rincer la bouche \\
\hline La lengua, -el paladar, -la garganta & La langue, -le palais, -la gorge \\
\hline La mandíbula, -la mejilla, -el labio & La mâchoire, -la joue, -la lèvre \\
\hline $\begin{array}{l}\text { La nariz, -la cara, -el rostro, -la oreja } \\
\text { (el oído) }\end{array}$ & La nez, -la figure, -le visage, -l'oreille \\
\hline $\begin{array}{l}\text { La barba (barbilla), -la barba (pelo), } \\
\text {-el bigote, -las patillas }\end{array}$ & $\begin{array}{l}\text { Le mentón, -la barbe, -la moustache, } \\
\text {-les favoris }\end{array}$ \\
\hline El hombro, -la espalda, -el pecho & L'épaule, -le dos, -la poitrine \\
\hline
\end{tabular}

7. El capítulo sobre enfermedades da cuenta de las dolencias, y algunos remedios, que debían resultar habituales en la sociedad de la época (constipado, ronquera, catarro, anginas, dolor de costado, cólicos, agujetas, dolor de muelas, flemón, sabañones, sarampión, viruelas, escarlata, tifus, pulmonía, guardar cama, tisanas, sinapismos, dieta, hacer gárgaras o llamar al médico).

8. Del tiempo, hora y edad enseña las voces y locuciones para hablar sobre el clima, las estaciones del año, los meses, las vacaciones, la medición del tiempo, el reloj o la duración de la vida.

9. La casa, en donde a través de la iglesia, del colegio, de los talleres y de algunos objetos de uso frecuente se describe cualquier casa religiosa de la época (oratorio, sacristía, vela, campanilla, palmatoria, cáliz, custodia, casulla, comulgar, procesión, claustro, patio, sala, estufa, mapa, peana, tejado, gabinete de física, laboratorio de química, escalera, enfermería, lavadero, fragua, bodega, cuadra, palomar, paraguas, bastón, onza, tijeras, navaja de afeitar, martillo, sierra).

10. Del vestido compendia sustantivos sobre ropas y atuendos (sombrero, gorro, camiseta, camisa, cuello, puño, botón, broche, ropa blanca, calzoncillo, calcetín, pantalón, bolsillo, hebilla, zapato, alpargata) y acciones relacionadas con ellos (faltar botones, abrochar, mudar de ropa, sonarse, tener la blusa descosida, hacer el uniforme, limpiar los vestidos, quitar las manchas).

11. De la comida reúne alimentos y menaje.

\begin{tabular}{|l|l|}
\hline Hemos comido arroz, -alubias, -habas, & Nous avons mangé du riz, -des haricots, \\
-guisantes, -lentejas, -garbanzos, & -des fèves, -des pois, -des lentilles, -des pois \\
-rábanos, -cebollas, -patatas (fritas, & chiches, -des radis, -des oignons, -des \\
-sin pelar) & $\begin{array}{l}\text { pommes de terre (rôties, -en robe } \\
\text { de chambre) }\end{array}$ \\
\hline
\end{tabular}




\begin{tabular}{|c|c|}
\hline $\begin{array}{l}\text { Nos han dado pescado, -bacalao, -atún, } \\
\text {-salmón, -anchoa, -truchas, -anguilas, } \\
\text {-escabeche }\end{array}$ & $\begin{array}{l}\text { On nous a donné du poisson, -de la morue, } \\
\text {-du ton, -du saumon, -de l'anchois, -des } \\
\text { truites, -des anguilles, -du poisson en } \\
\text { conserve (marine) }\end{array}$ \\
\hline $\begin{array}{l}\text { Nos han servido queso, -mantequilla, } \\
\text {-crema, -lacticinios }\end{array}$ & $\begin{array}{l}\text { On nois a servi du fromage, -du beurre, }- \text { de } \\
\text { la crème, -des laitages }\end{array}$ \\
\hline $\begin{array}{l}\text { Pase V. la sopera, -la fuente, -la botella, } \\
\text {-el jarro, -el plato, -el cazo, -el cucharón, } \\
\text {-la cucharita }\end{array}$ & $\begin{array}{l}\text { Faites passer la soupière, -le plat, -la } \\
\text { bouteille, -le pot à eau, -l'assiette, -la cuillère } \\
\text { à potage, -la cuillère á ragoût, -la petite } \\
\text { cuillère (à café) }\end{array}$ \\
\hline $\begin{array}{l}\text { ¿Dónde está su cubierto, su servilleta, } \\
\text { su servilletero (anillo), su cajón? }\end{array}$ & $\begin{array}{l}\text { Où est votre couvert, votre serviette, votre } \\
\text { anneau (coulant de serviette), votre } \\
\text { casier (tiroir)? }\end{array}$ \\
\hline
\end{tabular}

12. De la música recoge el vocabulario del canto, el solfeo, los instrumentos musicales o las notas.

13. Frases diversas es un capítulo heterogéneo, en el que se agrupa léxico de muy diversa temática (el teatro, sobre el enfado, la mentira, hacer un examen y otras expresiones difíciles de clasificar: me ha pisado, me ha dado un pisotón, esto es oro, -plata, -hierro, -plomo, -estaño, -bronce, -zinc, -níquel, -hojalata, ha sido sin querer, está chiflado, dar asco, es caro, son frioleras, -niñerías, -tonterías, me hace cosquillas, V. es un traidor, iqué barbaridad!, ies una lástima!, ¿en qué quedamos?...)

Como se aprecia en estos ejemplos, la Colección está formada por diversas unidades léxicas y sintácticas y su correspondencia en francés. La sencillez de esta presentación, en donde no hay lugar para marcas o informaciones de uso, obliga, en muchas ocasiones, a la utilización del paréntesis para aportar información que es necesaria o muy útil para el estudiante de una lengua. Así, por ejemplo, el autor distingue las frases familiares con la marca de uso fam. (ir tirando, estar así así, no inventó la pólvora, es un flojo rematado, está $V$. siempre papando moscas, me he pegado un trompazo, he caído patas arriba, los han dejado zapateros, tengo mucha galvana, es algo raro (estrafalario), es un bendito, es un bonachón, qué chasco (petardos, plancha) se ha llevado, está de hocico, le han dado una raspa, se quedó con un palmo de narices, está chiflado, le han dado una buena paliza, ivaya una trola (bola)!, tiene mucho pico, charla como una cotorra, echa las garras sobre cuanto le conviene, iqué tosco!, ibuena pieza es V.!). Otras veces se utiliza el paréntesis para

a) Introducir otros sinónimos o equivalentes léxicos, tanto en la columna española como en la francesa, que pueden resultar, en ocasiones, variantes diatópicas (como morisca) o diafásicas (como papá, mamá o las marcadas con fam.):

Vamos despacito (poco a poco) - On va tout doucement

Dé V. afectos (memorias, -recuerdos) a su hermano - Dites bien de choses à votre frère

Se porta bien, -muy bien - Il est sage, très sage (il se conduit bien, -très bien)

Se ha lucido - Il a brillé (il s'est disgintué)

Mire V. el tablero (el encerado) - Regardez le tableau

¿Ha puesto V. la dirección (las señas)? - Avez-vous mis l'adresse? 
Voy a escribir a mis padres, -a mi padre, -a mi madre (a papá, -a mamá) - Je vais écrire a mes parents, -à mon père, -à ma mère (à papa, -à maman)

Como V. guste - Comme il vous plaira (comme vous voudrez)

Un bofetón (una bofetada) - un soufflet (fam., une giffle, -une callote, -une tape)

Una hinchazón (un bulto) - une enflure

Escuece (pica) - Ça cuit (ça pique, -ça démange)

Ha venido el farmacéutico (boticario) - Le pharmacien (l'apothicaire) est venu

Granizo (piedra) - de la grêle

Los caminos están llenos de lodo (de barro) - Les chemins sont boueux (sont pleins de boue)

$\mathrm{El}$ oratorio (la capilla) - l'oratoire (la chapelle)

El viril (luneta) - La lunule

El cordón (cíngulo) - Le cordon

El suelo (piso) - Le sol

Un sillón (una butaca) - Un fauteuil

Un tiesto (maceta) de flores - Un pot de fleurs

La aljofaina (palangana) - La cuvette

Un fósforo (cerilla) - Une allumette

Una cuba (pipa) - Un tonneau

Una botella (pellejo) - Un outre

El ternero (choto) - Le veau

Un carrete (ovillo) de hilo - Un écheveau (une pelote) de fil

Le han roto los anteojos (gafas) - On lui a brisé les lunettes

Un azadón (morisca) $)^{6}$ - Une houe

Pañuelo (moquero) - Le mouchoir

¡Qué trozo más bonito (precioso)! - Quel beau (joli) morceau

El bajo (bombardino) - De la base

El contrabajo (bastuba) - De la contrabasse

¿Qué van a echar (representar) en el teatro? - Que va-t-on jouer (représenter) au théâtre?

Lo mismo (igual) da - Cela revient au même

La pajarilla (el bazo) - La rate

Tiene calentura (fiebre) - Il a de la fièvre

Es muy burlón (guasón) - Il est très moqueur

No se menee V., le voy a retratar (fotografiar) - Ne bougez pas (ne remuez pas), je vais vous photographies (je vais tirer votre portrait)

b) Incluir otras estructuras oracionales o sintagmáticas equivalentes semánticamente:

¿Qué edad (cuántos años) tiene V.? - Quel âge avez-vous?

Comeré algo para hacer aprecio (para darle gusto) - Je mangerai quelque chose pour vous faire plaisir

Hago el papel de... (hago de...) - Je joue (ja fais) le rôle de...

Que sea enhorabuena (le doy la enhorabuena) - Je vous félicite

Me siento mal (estoy mareado) - Je me sens mal

Se ha puesto malo (ha caído enfermo) - Il est tombé malade

Tengo ronquera (estoy ronco) - Je suis enroué

Tiene un catarro (está acatarrado) - Il a un catarrhe (un gros rhume)

Tengo dolor de costado (me duele el costado) - J'ai des points de côté (j'ai mal au côté)

c) Acotar, ante la simplicidad de los artículos lexicográficos y al tratarse de un repertorio contrastivo español-francés, la acepción o uso de que se trata; así diferencia entre "una cartera (grande) - d'un sous-main (portefeuille)" y "una cartera (de bolsillo) - d'un carnet 
(agenda, calepin)", entre una "goma (de borrar) - colle, gomme" y una "goma (de pegar) - de la gomme arabique", entre las doce (del día) o midi y las doce (de la noche) o minuit, entre "una escalera (fija) - un escalier" y "una escalera (de mano) - une échelle", entre "un dedo (de la mano) - un doigt" y "un dedo (del pie) - un orteil", entre "la barba (barbilla) - mentón" y "la barba (pelo) - barbe", entre "el pavo (común) - le didon" y "el pavo real - le paon" o para indicar que "la palma - la paume" es de la mano, que "el velo - le voile" es del cáliz, que "la pila - le bénitier" es de agua bendita, que "el colgador - le porte-manteau" es de la percha, que "el ojo - le trou" es de una aguja, que "un puño - une manchette" es de la camisa, que "la tecla - une touche" es del piano, que "el arco - l'arche" es del violín, que "la púa - la plume" es de la mandolina, que "la caña - l'anche" es del clarinete, que "la planta - la planta" es del pie o que "una jota - une danse" es un baile.

d) En el capítulo sobre los juegos, se utilizan los paréntesis para introducir otras formas sinónimas, que pueden ser o bien de la lengua general o bien voces especializadas del juego, o para introducir otras denominaciones de los juegos (el juego de los pozos u hoyos, de las bolas o bochas y del trompo o trompa); así, por ejemplo, en el juego del frontón el rastro ${ }^{7}$ es la raya, desquitarse equivale a estar en paz, volver a restar, chasser a renvoie-rend, estar a ellas a estar a iguales, frapper a prendre-saisir, en el juego de los pozos tapar es llenar, en el ajedrez las casillas son escaques, las piezas son peones y las torres son roques.

e) En otras ocasiones, se utilizan los paréntesis para añadir otras formas de la conjugación verbal: "Pronto se curará ( $V$., él)”, “¿Qué ha recetado el médico (a él, a $V$.)?”, "No nos toca a nosotros, no os toca a vosotros (no le toca a $V$., no les toca a $V d s$.)" o "¿Qué es lo que le duele ( $a$ V., a él)?”.

f) Finalmente, se usan para ofrecer una definición o descripción del referente: "el frontón (juego de pelota)" o "una alambrera (red metálica)".

Se trata, pues, de un repertorio sencillo y elemental que completaría y complementaría las clases de francés: con el aprendizaje de estas voces, locuciones y oraciones mejoraría el conocimiento de la lengua francesa y se desarrollarían las destrezas orales y, sobre todo, escritas de los estudiantes del Colegio.

\subsection{Explotación didáctica}

La Colección de voces, frases y locuciones castellanas con su traducción al francés debía resultar útil no solo desde el punto de vista léxico, sino que también podía ser explotada en otros niveles lingüísticos:

1. Oral, ya que el profesor podía ir pronunciando cada una de las voces y expresiones y pedir a los alumnos que las repitieran; como la mayoría de ellas pertenecen al entorno del alumno, podía incluso señalarlas para facilitar la adquisición. ${ }^{8}$

2. Morfológico, gracias a la presencia de la conjugación de algunas formas verbales en más de una persona y en más de un tiempo:

¿No entiende V.? - Vous ne comprenez pas?

$\mathrm{Ni}$ siquiera entiendo - Je ne comprends même pas 
No he entendido lo que V. ha dicho - Je n'ai compris ce que vous avez dit Ya entiendo bastante - Je comprends assez bien

No nos toca a nosotros - Ce n'est pas à nous

No os toca a vosotros (no le toca a $V$., no les toca a Vds.) - Ce n'est pas à vous

No les toca a ellos - Ce n'est pas à eux

Abrochar, abrocharse - Boutonner, se boutonner

Abroche V. el chaleco - Boutonnez votre gilet

Abróchese V. - Boutonnez-vous

V. no come nada hoy - Vous ne mangez rien aujourd'hui

Ya he comido bastante - J'ai déjà assez mangé

Ayer comimos de vigilia - Hier nous avons fait maigre

Hoy se puede comer carne - Aujourd'hui on peut faire gras (manger de la viande)

3. Sintáctico, pues un repertorio contrastivo español-francés permitía poner de manifiesto las diferencias gramaticales entre ambas lenguas, de modo que el alumno aprendía que caerse es un verbo pronominal en español pero no en francés, que doler se traduce por la construcción faire mal o que el verbo intransitivo gustar "agradar, parecer bien" se corresponde con aimer:

¿Me quiere V. regalarme esta estampa? - Voulez-vous me faire cadeau de cette image?

Se está siempre quejando por nada - Il est toujours à se plaindre pour des riens

Por poco me caigo - D'un peu plus je tombais

Me he caído - Je suis tombé

Me he hecho mucho daño - Je me suis fait très mal

Tengo dolor de muelas - J'ai mal aux dents

Me duelen las muelas - Les dents me Font mal

Me gusta, no me gusta - J'aime, je n'aime pas

Me gusta más, me gusta menos - J'aime mieux, j’aime moins

Me gusta tanto... - J'aime autant...

Me gusta poco, mucho - Je n'aime guère, j’aime beaucoup

Haga V. el favor de permitirme ir... Auriez-vous la bonté de me permettre d'aller...?

Ayez la bonté de me permettre d'aller...?

Voudriez-vous me permettre d'aller...?

Veuillez me permettre d'aller...?

Permettez-moi, s'il vous plaît, d'aller...?

Faites-moi le plaisir de me permettre d'aller...?

4. Semánticamente es muy útil la Colección porque el léxico aparece contextualizado gracias tanto a la distribución por ámbitos designativos como a las frases en que este se encuentra; así, es fácil diferenciar entre las acepciones de tocar como "hacer sonar un instrumento", "importar, ser de interés o conveniencia" y "haber llegado el momento oportuno de ejecutar lo expresado por el infinitivo que lo sigue", o las acepciones de sacar como "iniciar el juego", "poner fuera" o "conseguir, obtener":

Yo toco el cornetín - Je joue du piston

Eso no le toca a V. (no le importa) - Cela ne vous regarde pas

¿A quién le toca jugar? - A qui est-ce de jouer? 
Saque V. la pelota - Livrez (lancez) la balle

He sacado el libro del cajón - J'ai sorti le libre du bureau

Saca siempre buenas notas - Il obtient (il a) toujour de bonne notes

5. Este repertorio también podía resultar muy provechoso desde el punto de vista pragmático, pues evidencia en ocasiones cómo la situación establece determinados usos lingüísticos (por ejemplo, en el empleo de las fórmulas de tratamiento en los saludos a los religiosos, o también en las formas marcadas por fam.).

6. La Colección, en último lugar, atesora valiosa información sobre el contexto socio-cultural del Colegio de los Sagrados Corazones de Miranda de Ebro, que, posiblemente, puede hacerse extensivo a otras instituciones de la época: las vacaciones eran por Navidad y Pascuas de Resurrección; los cursos terminaban en junio; la Comunidad estaba formada por religiosos, hermanos estudiantes, novicios, apostólicos y colegiales, que podían a su vez ser externos o internos; no se podía hablar en español durante los recreos; o las comidas principales estaban compuestas por sopa, potajes, huevos fritos o pasados por agua, arroz, alubias, habas, guisantes, lentejas, garbanzos, rábanos, cebollas, patatas, ensalada de lechuga, de berros, de pepinos o de espinacas, bacalao, atún, salmón o truchas y carne de carnero, de gallina, de cordero, de ternero o de conejo.

Ahora bien, es seguramente el capítulo sobre los juegos el más rico léxica y etnográficamente, pues presenta una descripción pormenorizada del funcionamiento de cada uno de los juegos y el vocabulario en ellos utilizado. En este capítulo, hay voces generales documentadas también en otras zonas de la geografía española como pelota, ajedrez, damas, cometa, columpio, gavilán, zancos, honda, aro, lotería, dominó, rana, bolos, cara y cruz, tres en raya, gallina ciega, hinque, boliche, bolas o bochas, tala o marro; ${ }^{9}$ hay variantes como carabá o carabí-carabá (también llamado escondite inglés en otras zonas), trompo o trompa (también peonza), pozos u hoyos (o gua en otras geografías), correcalles (también llamado pídola, andaba la mula o burro), tío Gazapejos (cazador de conejos o en francés el père Jacob) o tuta ${ }^{10}$ (que en otras áreas se conocen como chito, caliche, tángana, tanga, tejo o calva); y hay formas como pimpasé o bolitas 'canicas' que los repertorios lexicográficos recogen como propias de Álava o Argentina, respectivamente (cfr. López de Guereñu, 1998 y DRAE). La Colección de Miranda de Ebro también da cuenta, seguramente por influencia francesa, del juego del croquet, denominación autorizada en la historia de los diccionarios del español tan solo por José Alemany y Bolufer en 1917 ("voz francesa. Juego que consiste en impulsar con un mazo bolas de madera, para hacerlas pasar bajo unos aros con arreglo a un orden determinado"), y que la Real Academia Española recoge en la edición del diccionario manual de 1927 como un anglicismo que debe evitarse por la forma española argolla, nombre con que es conocido este juego en tierras hispanas.

El léxico de la Colección evidencia, en cualquier caso, la experiencia de su autor de la vida escolar, su deseo por facilitar el aprendizaje de francés a sus alumnos y, en la selección de voces como morisca, rastro, carabá, trompo/a, correcalles, tuta, pimpasé o bolitas, su origen norteño o, al menos, su conocimiento de las voces de esa geografía. 


\subsection{Fuentes}

La llegada de la nueva centuria trajo a Europa, en menor medida a España, una renovación metodológica en la enseñanza de segundas lenguas: el desarrollo del método directo como alternativa al método gramática-traducción. En Francia, por ejemplo, fueron las propias autoridades ministeriales "quienes imponen el método directo, a pesar de numerosas voces de profesores, autores de manuales o asociaciones que se mostraban disconformes con la filosofía, el modo de entender la enseñanza de las lenguas modernas y las prácticas de clase del método directo”. Aunque con el paso del tiempo y la ausencia de una reflexión lingüística sobre objetivos, procedimientos y contenidos (“¿Cómo dar la clase? ¿Dónde aferrarse para marcar la progresión? ¿Cómo evaluar lo que se ha conseguido? ¿Cuándo puede decirse que el objetivo general se ha cumplido?”), el método directo fue desterrado de las clases de lengua, constituyó "un poderoso revulsivo que resquebrajó la tranquila conciencia de los profesores de lenguas vivas; significó el aldabonazo en una autocomplacencia didáctica de la época con un enfoque de la lengua que modificaba radicalmente no solo la forma de concebir su aprendizaje, sino que exigía un cambio en la actitud del profesor y en las relaciones en la clase" (Fernández Fraile, 1995, 252, 258 y 259).

Pese a estos intentos por modificar y cambiar la enseñanza de segundas lenguas, la publicación de la Colección demuestra que los materiales que se utilizaban en España no eran ni nuevos ni originales en la historia de la enseñanza de segundas lenguas, cuyo objetivo principal parecía seguir siendo la lectura, la traducción y la redacción: los repertorios temáticos, las listas de locuciones y los diálogos se venían utilizado como materiales didácticos desde la Antigüedad clásica.

El desconocimiento del griego y del latín obligó a la elaboración de repertorios temáticos bilingües que solían empezar por la descripción de Dios y continuar con el hombre, el reino animal, el reino vegetal y, en ocasiones, finalizar con el léxico de la muerte y la sepultura; distribución que heredan, en mayor o menor medida, casi todas las lenguas modernas. En los siglos XVI y XVII, momento en el que se conjugan varias circunstancias que condicionan nuestras relaciones con el exterior (España se abre a Europa, el latín es desconocido por buena parte de la población y es imposible su utilización como lingua franca, las colonias extrapeninsulares crecen y con ellas el comercio y el intercambio, las tropas han de mantener la paz en los territorios europeos conquistados y sus soldados necesitan aprender nuevas lenguas...), los objetivos de estas obras se modifican y de ser un instrumento de acercamiento a una lengua muerta pasan a reflejar las necesidades sociales, económicas y políticas de una sociedad que ha cambiado, convirtiéndose así en materiales útiles y muy prácticos para desenvolverse en situaciones cotidianas, pues, como señala Manuel Alvar Ezquerra (2013, 19-20), se desarrollaron "con una finalidad práctica inmediata, y de eminente carácter didáctico, en las que se hace una clasificación de la realidad extralingüística, esto es, de las ideas que tenemos de las cosas, de manera que el mundo queda parcelado, repartiéndose el vocabulario a lo largo de esas divisiones”.

Del mismo modo, los diálogos y las listas de locuciones (también de sentencias y refranes) cuentan con una larga tradición, pues, como las nomenclaturas, se vio, sobre todo a partir del siglo XVI, que eran unas herramientas muy útiles para aprender una segunda lengua: los Colloquia de Berlaimont (1556), los Diálogos en español y francés de César Oudin (1604) y Antonio Oudin (1650), los Diálogos familiares de Juan de Luna (1623), los Discursos familiares con algunos proverbios de Stephan Barnabé (1660), los Diálogos 
apacibles compuestos en castellano y traducidos en toscano de Lorenzo Franciosini (1687), los Diálogos ingleses y españoles de Félix Antonio de Alvarado (1718), los Diálogos en español y francés de Francisco Sobrino (1708), los Diálogos familiares de Esteban Terreros (1771), los Diálogos apacibles castellanos y alemanes a uso de ambas naciones de Johann M. Minner (1813), los Diálogos familiares españoles e ingleses de Felipe Fernández (1822), los Diálogos clásicos de Charles Morand y Cristóbal Pla y Torres (1827), la Guía de la conversación de Melchor Núñez de Taboada (1833), los Diálogos familiares de José de Urcullu (1837), la Colección miscelánea de frases familiares y diálogos de etiqueta de Emanuel del Mar (1844), las Conversaciones de Eugenio de Ochoa (1853), los Diálogos españoles-árabes de Pedro María del Castillo y Olivas (1860), El intérprete chino de José de Aguilar (1861), las Frases usuales de Venancio María de Abella (1872), las Frases usuales y diálogos en castellano y vascuence de Juan María de Eguren (1876), entre otros muchos, son buena muestra de ello ${ }^{11}$ (Alvar Ezquerra, 2013; Chevalier, 1988; Colombo, 1998; Sánchez Pérez, 1992). El Padre del Colegio de los Sagrados Corazones de Miranda de Ebro solo se limitó a adaptar estos materiales a las necesidades de sus alumnos.

\section{CONCLUSIONES}

La Colección de voces, frases y locuciones castellanas con su traducción al francés, pese a no ser original, debió resultar muy útil a los alumnos del Colegio de Miranda. El vocabulario y las locuciones que recogen y los diálogos que contienen -muy beneficiosos como ejercicios de traducción o como muestras de los usos gramaticales y pragmáticos de una lengua- permiten conocer hoy con qué materiales se aprendía francés en la España de principios de siglo XX, cómo se enseñaba una lengua fuera de sus fronteras o cómo se resolvían los problemas metodológicos y lingüísticos que ello acarreaba.

El análisis de este texto (que no se cita en los catálogos habituales de francés como lengua extranjera) solo tiene como objetivo contribuir a la historia de la enseñanza del francés en España, a la historia de la Didáctica del francés (lengua cuyo estudio se multiplica a finales del siglo XIX y principios del XX, pues se convierte en una materia necesaria en el currículum del alumno) y a la historia, todavía por hacer, de la Lexicografía escolar española.

\section{NOTAS}

* Este trabajo se enmarca dentro del Proyecto de Investigación "Biblioteca Virtual de la Filología Española. Fase II. Consolidación, mejora y ampliación de los datos y de la web. Estudio de los materiales contenidos" (FFI2014-5381-P), dirigido por Manuel Alvar Ezquerra. Agradezco a Manuel Alvar Ezquerra y a Javier Suso López la ayuda prestada para la localización, análisis y contextualización de este trabajo.

1 Fue publicada parcialmente en 1961 con el título "Avec quels livres les Espagnols apprenaient le français (1520-1850)" y de forma completa en 2008 como La enseñanza del francés en España hasta 1850. ¿Con qué libros aprendían francés los españoles?

2 La información sobre la historia del Colegio procede de "Breve resumen histórico del Colegio" de Luis Ángel Valcárcel, http://www.ssccmiranda.com/images/pdf/resumen-historiassccmiranda.pdf, de "Centenario de la llegada de la Congregación a Miranda" de Ramiro Goldáraz, http://www.ssccmiranda.com/images/pdf/centenario-llegada-congregacionmiranda.pdf, de "Los primeros pasos del Colegio" de Víctor Pérez, http://www.ssccmiranda. com/images/pdf/los-primeros-pasos-del-colegio.pdf, y de "Orígenes de la Congregación en 
Miranda" de Javier Flamarique, http://www.ssccmiranda.com/images/pdf/origenes-de-lacongregacion-en-miranda.pdf.

3 Vid. "Los primeros pasos del Colegio" de Víctor Pérez, http://www.ssccmiranda.com/images/ pdf/los-primeros-pasos-del-colegio.pdf.

4 Muchos de los ejemplares de estas obras, así como de otras ediciones y reimpresiones, pueden consultarse en libre acceso en la Biblioteca Virtual de la Filología Española, www.bvfe.es.

5 Utilizo el ejemplar digitalizado de la Biblioteca de Castilla y León, Estudios Castellanos y Leoneses, Valladolid, con signatura G-F 14637, cfr. en la Biblioteca Virtual de la Filología Española (www.bvfe.es) http://www.bvfe.es/directorio-bibliografico-diccionarios-vocabulariosglosarios-tratados-y-obras-lexicografia/18321-coleccion-de-voces-frasesylocuciones-castellanas -con-su-traduccion-al-frances-compuesta-por-un-padre-del-colegio-de-los-sagrados-corazones -de-miranda-de-ebro.html.

6 La azada se llama morisca en La Rioja, algunas zonas de Castilla y en Vizcaya; así lo testimonian Terreros, 1786-1788, que era de Trucíos, Álava; Hernández Alonso, 2001; Martínez Izquierdo, 2004; Pastor Blanco, 2004; Goicoechea, 1961, y Alvar, 1979-1980, mapa 99 y 1999, mapa 282 en el Barcina de los Montes, municipio de Oña, no muy lejos de Miranda de Ebro.

7 La raya o "línea de faltas en la pared" de los juegos de pelota, entre ellos el frontón, se documenta en el norte de Burgos y en el oeste de La Rioja como rastro (ALEANR, vol. IX, mapa 1164).

8 Uno de los pocos testimonios que existen en la historia de las nomenclaturas sobre la utilización de estos repertorios lo proporciona Juan María de Eguren, quien en el prólogo de su Método práctico para enseñar el castellano en las escuelas vascongadas (Vitoria, Seminario Católico Vasco-Navarro, 1867), explica que "Al frente de cada uno de estos grupos [de no más de diez alumnos] se coloca un instructor con un ejemplar de este método en la mano, y recita las palabras comprendidas en el vocabulario núm. 1, en la forma en que van escritas, esto es, primero en vascuence y después en castellano, haciéndolas repetir a todos los niños del grupo con precisión y claridad, según que él las va diciendo. Solamente deben decirse diez o doce palabras, o el número de voces que en cada ejercicio de estos puedan aprender de memoria los niños, teniendo el cuidado de señalar con la mano al mismo tiempo las cosas que se espresan con dichas palabras, siempre que fuere posible, para que de este modo comprender bien los niños su significación. Por ejemplo, al decirles burua, la cabeza; arpeyuia, la cara; beguiac, los ojos y las demás contenidas en el vocabulario, debe el instructor señalar con la mano la cabeza, la cara, los ojos, y hacer que los niños del grupo repitan la misma operación, procurando siempre que esto tenga lugar con el mayor orden y precisión" (García Aranda, 2009).

$9 \mathrm{Al}$ marro que se refiere la Colección, por la descripción que hace, es al "juego en que, colocados los jugadores en dos bandos, uno enfrente de otro, dejando suficiente campo en medio, sale cada individuo hasta la mitad de él a coger a su contrario. El arte consiste en huir el cuerpo, no dejándose coger ni tocar, retirándose a su bando. Este juego se conoce con otros varios nombres", y no al "juego que se ejecuta hincando en el suelo un bolo u otra cosa, y, tirando con el marrón, gana quien lo pone más cerca" (DRAE).

10 La tuta, según el DRAE, es voz usada en Álava, Cantabria y Vizcaya.

11 Algunos de estos textos están digitalizados en la Biblioteca Virtual de la Filología Española, www.bvfe.es.

\section{REFERENCIAS BIBLIOGRÁFICAS}

ALVAR, M. 1961-1973. Atlas lingüístico y etnográfico de Andalucía, con la colaboración de Llorente, A. y Salvador, G. Granada: Universidad de Granada/CSIC, 6 vols. 
.1979-1980. Atlas lingüístico y etnográfico de Aragón, Navarra y La Rioja, con la colaboración de Llorente, A., Buesa, T. y Alvar, E. Zaragoza/Madrid: Diputación Provincial de Zaragoza/CSIC, 12 vols.

. 1995. Atlas lingüístico y etnográfico de Cantabria, con la colaboración de Mayoral, J. A., Alvar, C., Nuño, M. P., Caballero, M. C., Corral, J. B. y Alvar, E. Madrid: Arco/Libros, 2 vols. y Cultura.

1999. Atlas lingüístico de Castilla y León. Valladolid: Consejería de Educación

ALVAR EZQUERRA, M. 2013. Las nomenclaturas del español. Siglos XV-XIX. Madrid: Liceus.

. Biblioteca virtual de la Filología Española. Disponible en: www.bvfe.es

BRUÑA CUEVAS, M. 2004. "Les dictionnaires encyclopédiques bilingües françaisespagnol”, en Suso López, J. y López Carrillo, R. (eds.), Le français face aux défis actuels. Histoire, langue et culture, tomo II. Granada: Universidad de Granada, 35-44.

CAZORLA VIVAS, M. C. 2002. Lexicografía bilingüe de los siglos XVIII y XIX con el español y el francés. Madrid: Universidad Complutense de Madrid.

. 2014. Diccionarios y estudio de lenguas modernas en el Siglo de las Luces. Tradición y revolución lexicográfica en el ámbito hispano-francés. Madrid: Liceus.

CHEVALIER, J. C. 1988. "Les dialogues médiévaux. Origines, filiations, méthodes. Quelques pistes”, Documents pour l'enseignement du français langue étrangère ou seconde, 22, 17-26.

COLOMBO TIMELLI, M. 1998. "Dialogues et phraséologie dans quelques dictionnaires plurilingues du XVI siècle", Documents pour l'enseignement du français langue étrangère ou seconde, 22, 27-59.

DOMÍNGUEZ ORTIZ, A. 1989. Carlos III y la España de la Ilustración. Madrid: Alianza.

FERNÁNDEZ FRAILE, M. E. 1995. La enseñanza/aprendizaje del francés como lengua extranjera en España (1767-1936): objetivos, contenidos y procedimientos. Granada: Universidad.

FERNÁNDEZ FRAILE, M. E. y SUSO LÓPEZ, J. 1999. La enseñanza del francés en España (1767-1936). Estudio histórico: objetivos, contenidos, procedimientos. Granada: Método.

FISCHER, D. y GARCÍA BASCUÑANA, J. F. 2004. Repertorio de gramáticas y manuales para la enseñanza del francés en España (1565-1940). Barcelona: Publicaciones y Promociones Universitarias.

FLAMARIQUE, J. (s.f.). “Orígenes de la Congregación en Miranda”. Disponible en: http:// www.ssccmiranda.com/images/pdf/origenes-de-la-congregacion-en-miranda.pdf

GARCÍA ARANDA, M. A. 2009. "La enseñanza del español en las escuelas del País Vasco: la labor lexicográfica de Juan María de Eguren (1867-1876)”, Boletín de Filología de la Universidad de Chile, XLIV (1), 97-124.

GARCÍA BASCUÑANA, J. F. 1996. "Contribución al estudio de los diccionarios bilingües francés-español / español-francés: aproximación histórica y metodológica”, en Forgas Berdet, E. (coord.), Léxico y diccionario. Tarragona: Universitat Rovira i Virgili, Departament de Filologies Romàniques, 91-104.

. 2005. "Materiales para la enseñanza del francés en España: aproximación a los manuales publicados entre los Siglos XVI y XX", Revista Interuniversitaria de Formación del Profesorado, 19 (2), 129-144. 
GARCÍA BASCUÑANA, J. F., LÉPINETTE, B. y ROIG, C. (eds.). 1996. Documents pour l'histoire du français et sa présence dans la Péninsule Ibérique. Actes du colloque de la SIHFLES tenu à Tarragone (Université Rovira i Virgili) du 28 au 30 septembre 1995, Décembre, 18.

GARCÍA MOUTON, P. y FERNÁNDEZ MORENO, F. 2003. Atlas lingüístico y etnográfico de Castilla-La Mancha. Alcalá de Henares: Universidad de Alcalá. Disponible en: http://www2.uah.es/alecman.

GEMMINGEN, B. von y HÖFLER, M. (eds.). 1988. La lexicographie française du XVIIIe au XXe siécle. Travaux de Linguistique et Philologie, XXVI.

GOICOECHEA, C. 1961. Vocabulario riojano. Madrid: RAE.

GOLDÁRAZ, R. (s.f.). "Centenario de la llegada de la Congregación a Miranda”. Disponible en: http://www.ssccmiranda.com/images/pdf/centenario-llegada-congregacion-miranda.pdf

HERNÁNDEZ ALONSO, C. (coord.). 2001. Diccionario del castellano tradicional. Valladolid: Ámbito.

LÓPEZ DE GUEREÑU GALARRAGA, G. 1998. Voces alavesas, $2^{\mathrm{a}}$ edición. Bilbao: Euskaltzaindia.

MARTÍNEZ IZQUIERDO, A. 2004. Diccionario de voces riojanas. Logroño: Instituto de Estudios Riojanos.

PASTOR BLANCO, J. M. 2004. Tesoro léxico de las hablas riojanas. Logroño: Universidad de La Rioja.

PÉREZ, V. (s.f.). "Los primeros pasos del Colegio". Disponible en: http://www. ssccmiranda.com/images/pdf/los-primeros-pasos-del-colegio.pdf.

QUEMADA, B. 1968. Les dictionnaires du français moderne (1539-1863). París: Didier.

Real Academia Española. 2001. Nuevo Tesoro Lexicográfico de la Lengua Española. Madrid: Espasa-Calpe, edición en DVD. Disponible también en: http://ntlle.rae.es/ ntlle/SrvltGUILoginNtlle. . 2014. Diccionario de la lengua española, $23^{\text {a }}$ edición. Madrid: Espasa.

SÁNCHEZ PÉREZ, A. 1992. Historia de la enseñanza del español como lengua extranjera. Madrid: SGEL.

. 1997. Los métodos en la enseñanza de idiomas. Evolución histórica y análisis didáctico. Madrid: SGEL.

SIERRA SORIANO, A. 2010. "La Lexicographie français-espagnol: tradition et modernité", Quaderns de Filología. Estudis linguistics, XV, 219-235.

SIMON PALMER, M. C. 1972. La enseñanza privada seglar de Grado medio en Madrid (1820-1868). Madrid: Instituto de Estudios Madrileños.

SUÁREZ GÓMEZ, G. 1956. La enseñanza del francés en España (Comentario a una bibliografía establecida hasta 1850). Tesis doctoral inédita. Madrid: Universidad Complutense de Madrid.

. 1961. "Avec quels livres les Espagnols apprenaient le français (1520-1850)", Revue de littérature comparée, 35, 159-171, 330-346 y 512-523.

- 2008. La enseñanza del francés en España hasta 1850. ¿Con qué libros aprendían francés los españoles? Barcelona: Promociones y Publicaciones Universitarias.

SUSO LÓPEZ, J. y FERNÁNDEZ FRAILE, M. E. 2008. Repertorio de manuales para la enseñanza del francés en España (siglo XX): con qué libros los españoles hemos aprendido francés en el siglo XX. Granada: Comares. 
TERREROS y PANDO, E. 1786-1788. Diccionario castellano con las voces de ciencias y artes y sus correspondientes en las tres lenguas francesa, latina e italiana. Madrid: Imp. de la viuda de Ibarra (t. I, 1786; t. II, 1787; t. III, 1788).

VALCÁRCEL, J. A. 1798. Agricultura general y Gobierno de la casa de campo, tomo I. Madrid: José Estevan.

VALCÁRCEL, L. A. (s.f.). “Breve resumen histórico del Colegio”. Disponible en: http:// www.ssccmiranda.com/images/pdf/resumen-historia-ssccmiranda.pdf.

VERDONK, R. A. 1991. "La lexicographie bilingue espagnol-français, français-espagnol”, en Hausmann, F. J., Reichmann, O., Wiegand, E. y Zgusta, L. (eds.), Wörterbücher / Dictionaries / Dictionnaires. Ein internationales Handbuch zur Lexikographie / An International Encyclopedia of Lexicography / Enciclopédie internationale de lexicographie, 3. Berlín-Nueva York: De Gruyter, 2976-2987.

\section{NOTA SOBRE LA AUTORA}

M. ${ }^{a}$ Ángeles García Aranda es profesora Titular de Universidad en el Departamento de Lengua Española y Teoría de la Literatura y Literatura Comparada de la Universidad Complutense de Madrid, España. 